\title{
Patient selection for transcatheter aortic valve replacement: how to choose an appropriate candidate
}

\author{
(DIvana Jurin*, \\ (DTomislav Šipić, \\ (DDaniel Unić, \\ Digor Rudež, \\ (DŠime Manola, \\ DIrzal Hadžibegović
}

University Hospital Dubrava, Zagreb, Croatia

\begin{abstract}
KEYWORDS: transcatheter aortic valve implantation, aortic stenosis, patient selection, risk. CITATION: Cardiol Croat. 2021;16(9-10):306. | https://doi.org/10.15836/ccar2021.306
\end{abstract}

*ADDRESS FOR CORRESPONDENCE: Ivana Jurin, Klinička bolnica Dubrava, Avenija Gojka Šuška 6, HR-10000 Zagreb, Croatia. / Phone: +385-95-559-387 / E-mail: ivanajurin1912@gmail.com

ORCID: Ivana Jurin, https://orcid.org/0000-0002-2637-9691 • Tomislav Šipić, https://orcid.org/0000-0001-8652-4523 Daniel Unić, https://orcid.org/0000-0003-2740-4067 • Igor Rudež, https://orcid.org/0000-0002-7735-6721 Šime Manola, https://orcid.org/0000-0001-6444-2674 • Irzal Hadžibegović, https://orcid.org/0000-0002-3768-9134

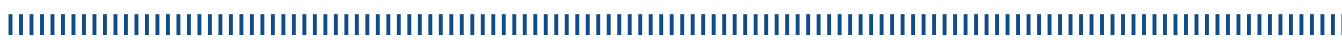

Transcatheter aortic valve implantation (TAVI) has rapidly evolved over the past decade in response to growing population of older adults with aortic stenosis ${ }^{1}$. Initially, TAVI was approved for patients determined to be inoperable, but recently has expanded to those who were qualified as intermediate and low risk. The appropriate patient for a TAVI procedure typically has symptomatic senile degenerative AS of a trileaflet valve but recently indications for TAVI have expanded beyond typical and therefore choosing the optimal candidate has become more challenging. Patient selection for TAVI is based on accurate clinical and anatomical assessment of aortic stenosis. Patient selection is crucial when determining whether a patient is likely to benefit from catheter-based intervention as opposed to surgical intervention as well as determine whether patient is ill with the aortic stenosis or ill because of the aortic stenosis. This is because there are several clinical and anatomical aspects to be considered by the Heart team that favors a particular approach to treating severe aortic valve disease. The Heart team needs to discuss and evaluate expected quality of life versus risk of complications ${ }^{2}$. Besides of proper patient selection, the safety and efficacy of prothesis implantation depends on procedural guidance which is based on a multimodality imaging approach. There are several patient factors and comorbidities which are associated with a poor post-TAVI outcome. These comorbidities include respiratory conditions associated with chronic lung disease, chronic kidney disease as well as frailty. Mobility, nutrition, and cognition in patients have been incorporated into many preoperative evaluations for selecting TAVI patients due to the relationship with poorer outcomes. Identifying the comorbidities which lead to poor outcomes post-TAVI remains a particularly challenging issue. Larger trials are required to determine which subpopulations of patients stand to benefit most from this procedure.
RECEIVED:

August 1, 2021

ACCEPTED:

August 5, 2021

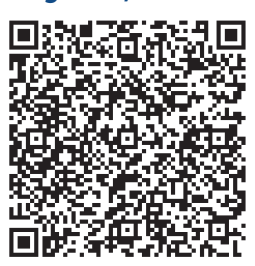

$\square$ Cardiologia Croatica 2021;16(9-10):306.

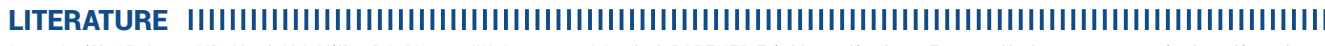

1. Smith CR, Leon MB, Mack MJ, Miller DC, Moses JW, Svensson LG, et al; PARTNER Trial Investigators. Transcatheter versus surgical aortic-valve replacement in high-risk patients. N Engl J Med. 2011 Jun 9;364(23):2187-98. https://doi.org/10.1056/NEJMoal103510

2. Sintek M, Zajarias A. Patient evaluation and selection for transcatheter aortic valve replacement: the heart team approach. Prog Cardiovasc Dis. 2014 May-Jun;56(6):572-82. https://doi.org/10.1016/j.pcad.2014.02.003 